\title{
Atraumatic maxillary sinus elevation using threaded bone dilators for immediate implants. A three-year clinical study
}

\author{
José-Luis Calvo-Guirado ${ }^{1}$, Gerardo Gómez-Moreno ${ }^{2}$, Laura López-Marí ${ }^{3}$, Antonio-José Ortiz-Ruiz ${ }^{4}$, Ja- \\ vier Guardia-Muñoz ${ }^{5}$
}

\footnotetext{
${ }^{1}$ Senior Lecturer, Adult Integrated Dentistry Clinic and Director of Implantology Masters Program, Faculty of Medicine and Dentistry, the University of Murcia, Spain

${ }^{2}$ Associate Lecturer in Pharmacological Interactions in Dentistry, Faculty of Dentistry, the University of Granada, Spain

${ }^{3}$ Master of Integrated Dentistry and Implantology, University of Murcia, Spain

${ }^{4}$ Senior Lecturer in Integrated Pediatric Dentistry, Faculty of Medicine and Dentistry, the University of Murcia, Spain

${ }^{5}$ Doctor of Dentistry. Collaborator in Pharmacological Interactions in Dentistry, Faculty of Dentistry, University of Granada, Spain
}

Correspondence:

Mozart $N^{o} 1,1^{\circ} G$

30002 Murcia, Spain

joseluis.calvo@um.es

Received: 08/11/2008 Accepted: 28/11/2009
Calvo-Guirado JL, Gomez-Moreno G, Lopez-Mari L, Ortiz-Ruiz AJ, Guardia-Muñoz J. Atraumatic maxillary sinus elevation using threaded bone dilators for immediate implants. A three-year clinical study. Med Oral Patol Oral Cir Bucal. 2010 Mar 1:15 (2):e366-70.

http://www.medicinaoral.com/medoralfree01/v15i2/medoralv15i2p366.pdf

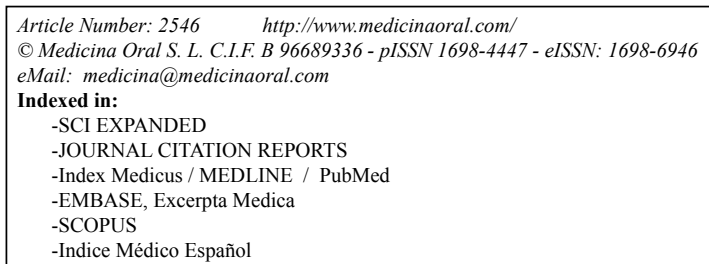

\begin{abstract}
Objective: The aim of this study was to evaluate the efficacy of sinus floor elevation using sequential bone dilators. Materials and Methods: Thirty patients took part in the study (18 women and 12 men) with ages ranging between thirty-six and sixty-three years, selected according to inclusion and exclusion criteria, who showed a bone deficit in the upper posterior alveolar margin of 5-8 $\mathrm{mm}$ in height. Sixty expanded platform internal connection implants were placed with diameters of $4 / 5 / 4 \mathrm{~mm}$ and lengths varying between $10(\mathrm{n}=10)$ and $11.5 \mathrm{~mm}(\mathrm{n}=50)$. Results: Data obtained were analyzed using SPSS 15.0 software. The average intra-sinus bone gain with MP3 biomaterial of porcine origin was $4.13+/-0.97 \mathrm{SD} \mathrm{mm}$ at the moment of implant placement, $3.90+/-1.15 \mathrm{SD} \mathrm{mm}$ after twelve months, $3.74+/-1.05 \mathrm{SD}$ mm after 24 months and $3.62+/-1.75 \mathrm{SD} \mathrm{mm}$ after 36 months. Two implants were lost at the moment of prosthesis placement. Conclusions: Alveolar lifting technique in the upper maxilla using bone dilators achieved a $96.6 \%$ implant success rate after a three-year follow-up. Intra-sinus bone biomaterial remodeling was $0.51+/-0.08 \mathrm{~mm}$ from day zero to the thirty-six-month follow-up. This is a procedure that reduces the amount of surgery necessary and is of both aesthetic and functional benefit to the patient.
\end{abstract}

Key words: Bone dilator, osteotome, bone expansion, dental implants, atraumatic sinus lifting. 


\section{Introduction}

An edentulous upper posterior maxilla generally presents bone reduction both in height and width of the alveolar process due to atrophy and to the neumatization of the maxillary sinus, making immediate implant placement impossible (1). Residual bone in the upper maxilla often shows low bone density classified by Misch as type D3, which has been described as a cause of increased rates of implant failure (2). There are numerous techniques available for creating a sufficient volume of supporting bone in and around the maxillary sinus (2-4) but some of these treatments are complex and require specific surgical training; they are seen to achieve implant survival rates of between 91 and $98 \%(5,6)$.

Boyne et al. have described the formation of bone in the implant's apical portion stabilized at the crestal level (7). The use of osteotomes has been developed in order to simplify implant placement in narrow osseous margins resulting from resorption $(8,9)$.

In 1994, Summers introduced a maxillary sinus lifting technique using osteotomes, in which bone is added to the apical part of the implant to improve stability; this technique can be employed whenever there is a $5-7 \mathrm{~mm}$ residual margin. He also devised the first sequential bone dilators of cylindrical-conical shape, each instrument in the sequence having a progressively increasing diameter, so that the base of each corresponds in diameter to the active portion of the next, allowing immediate implant placement. $(10,11)$.

The aim of this prospective clinical study was to evaluate (using radiography) apical bone remodeling around immediate implants after sinus lifting using bone dilators over a thirty-six month follow-up period, and by so doing to describe a series of clinical cases.

\section{Materials and Methods}

Thirty patients (eighteen women and twelve men aged between thirty-six and sixty-three years) took part in the study; all presented atrophy affecting both height and width of the posterior upper maxillary. Sixty internal connection implants were placed in the thirty patients; these were Osseotite ${ }^{\circledR}$ Certain $\AA$ PREVAIL ${ }^{\circledR}$ (Biomet $3 \mathrm{i}$ Implants Innovations Inc, Palm Beach Gardens, FL, USA) with a diameter of $4 \mathrm{~mm}$ and lengths of between $10 \mathrm{~mm}$ $(\mathrm{n}=10)$ and $11.5 \mathrm{~mm}(\mathrm{n}=50)$. The abbreviation $4 / 5 / 4 \mathrm{~mm}$ corresponds to an implant with a $4 \mathrm{~mm}$ prosthetic connection, $5 \mathrm{~mm}$ platform and $4 \mathrm{~mm}$ body. All implants were placed and monitored through the follow-up period by the same surgeon between January 2005 and January 2008. All patients were partly edentulous in one or two upper maxillary segments (Kennedy classification I, II and III) and all gave their informed consent in full awareness of the possible risks and benefits of the procedure. The risks described to them included infection, pain, bone graft loss and loss of one or more implants during the study period.

\section{Inclusion criteria}

Panoramic and periapical radiographs were made for all patients. The following criteria were requirements for inclusion in the study:

1. Partially or totally edentulous in the upper posterior maxilla and so requiring implants.

2. The implants required were at least $8 \mathrm{~mm}$ in length.

3. Residual bone height of between $5 \mathrm{~mm}$ and $8 \mathrm{~mm}$.

4. At least $1 \mathrm{~mm}$ of periimplant bone around the implants.

5. If a patient smoked, that consumption did not exceed ten cigarettes per day.

\section{Exclusion criteria}

1. Uncontrolled diabetes.

2. Patients irradiated within the previous twelve months. 3. Patients who had received chemotherapy during the previous twelve months.

4. Uncontrolled periodontal disease.

5. Acute infection of the maxillary sinus or a history of persistent sinus infection.

6. Heavy smokers.

7. Psychological disorders (including depression and nervous conditions) that, in the opinion of the research team, might make dental treatment unsustainable.

8. Possible difficulties in maintaining a regime of postimplant surgery care.

All implants were placed immediately after the application of convex and concave bone dilators for sinus floor lifting by means of the introduction of porcine bone MP3 Osteobiol ${ }^{\circledR}$ of $600 \mu \mathrm{m}$ (Osteogenos, Madrid, Spain). Residual bone height (RBH) varied between 5 and $8 \mathrm{~mm}$ for all patients (Fig. 1). All implants were rehabilitated with metal-ceramic crowns eighteen weeks after surgery. Post surgery medication consisted of chlorhexidine mouthwashes at $0.02 \%$ twice a day for fourteen days, $1 \mathrm{gr}$. of amoxicillin twice a day for six days $(500 \mathrm{mg}$ of erythromycin twice a day for those patients allergic to penicillin) and $600 \mathrm{mg}$ of ibuprofen three times a day. Sutures were removed after eight to ten days.

\section{Radiographic analysis}

The objectives of radiograph analysis were:

1 . To evaluate primary implant anchorage immediately after surgery.

2. To evaluate changes to intra-sinus bone height and remodeling resulting from elevation with osteotomes.

All patients underwent periapical panoramic radiographs on the day of surgery, at the time of prosthesis placement and at twelve, twenty-four and thirty-six months. The radiographs were made using the parallel technique (Hawe Neos Super-Bite, Hawe Neos Dental, Bioggio, Switzerland) in RVG (radiovisiograph) format. Analysis of bone growth measurements and remodeling were carried out with digital image processing software Visilog 4.15 (Neosis, Orsay, France), which measured 


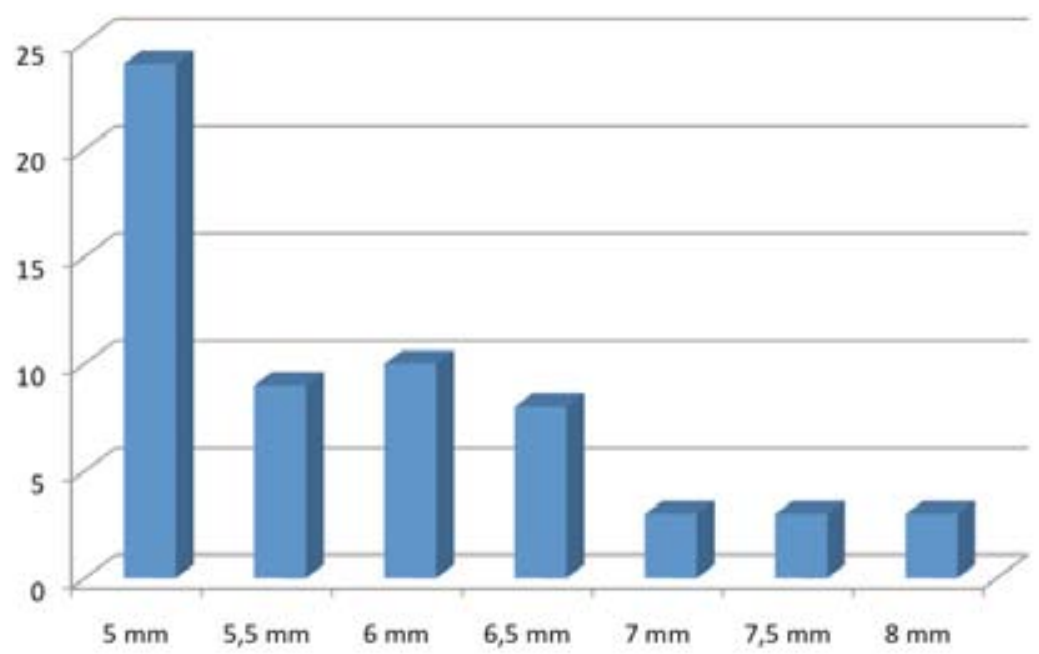

Fig. 1. Graph showing initial bone height of alveolar ridge.

the distance between two points: from implant collar to first bone contact.

Each radiovisiograph was calibrated by calculating the length of each implant in order to evaluate a normalization factor, avoiding magnification and alterations to implant data. A Hawe Neos ${ }^{\circledR}$ radiographic paralleling device was used, and radiographs were made by three different practitioners who obtained three takes from which average values were obtained.

Posterior residual bone height was measured both mesially and distally around each implant, from implant collar to maxillary sinus floor (Fig. 2). The quantity of bone elevated with biomaterial in the sinus was also evaluated Comparisons were made between the measurements taken immediately following surgery, when the prosthesis was fitted, at twelve, twenty-four and thirty-six months. The quantity of bone in the sinus pushed up by the osteotomy was measured by tracing a line perpendicular to the implant's central axis at the base of the maxillary sinus and then tracing a vertical line from sinus base at the middle of the implant to the most apical part of the elevated bone (Fig. 3).

\section{Success Criteria}

Success criteria were as described by Albrektsson et al. (12):

a) Absence of clinical movement.

b) Absence of pain.

c) Absence of periimplant infection.

d) Absence of radioluscence around the implant.

\section{Statistical analysis}

An average percentage success rate with standard deviation was calculated after an eighteen-week healing period. Differences between averages and between groups were analyzed using a non-parametric Mann-Whitney

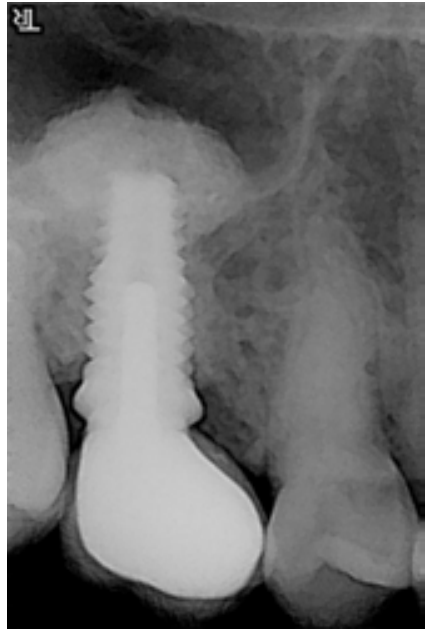

Fig. 2. Evaluation of bone remodeling after three years.

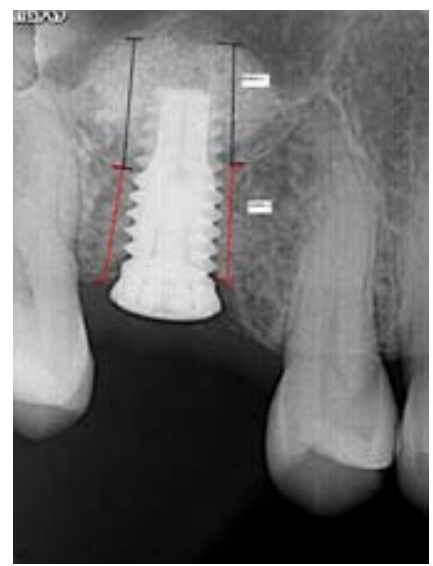

Fig. 3. Radiovisiograph of an implant indicating the area of residual bone (zone one, red) and bone in the maxillary sinus augmented with biomaterial of porcine origen (zone 2, black). 
test with a significance level of $p<0.05$. All statistical data were processed using SPSS 15.0 software for Windows (Chicago, Illinois, U.S.A.).

\section{Results}

The patients selected were treated and monitored between January 2005 and January 2008. Thirty patients were included in the study, after undergoing sinus floor lifting with bone dilators and evaluating bone increase by means of periapical radiovisiographs. The patients recruited for the study were eighteen women $(60 \%)$ and twelve men (40\%) with an average age of $53.6 \pm 11.2$ years, ages ranging between thirty-six and sixty-three years. They received sixty implants and sinus lifting with sequential threaded bone dilators.

Fifty implants (83.3\%) were of $11.5 \mathrm{~mm}$ and ten (16.6\%) were of $10 \mathrm{~mm}$. Bone quality was determined as type IV bone during implant surgery according to Lekholm and Zarb classification.

Only two patients smoked, consuming fewer than five cigarettes per day. Implants were distributed as follows: fourteen in second premolar sites, ten in first molar sites and six in second molar sites. Three out of the sixty sites elevated with bone dilators presented perforation of the sinus membrane.

Complications which arose after surgery consisted of two cases of nose bleeding and two implant failures; one implant of $10 \mathrm{~mm}$ (tooth 14) and one of $11.5 \mathrm{~mm}$ (tooth 26), which were lost at the eighteen week mark when the final prosthesis was placed.

From the first day when surgery was carried out until the thirty-six month follow-up, the remaining implants were clinically firm and stable, with a final success rate of $96.6 \%$.

\section{Radiograph Analysis}

Changes to bone height elevated in the sinus with biomaterial were observed mesially and distally over the thirty-six month evaluation. On the mesial side of the implant average elevated bone at the time of surgery was $4.25 \pm 1.05 \mathrm{SD} \mathrm{mm}, 3.92 \pm 1.2 \mathrm{SD} \mathrm{mm}$ at twelve months, $3.71 \pm 0.8 \mathrm{SD} \mathrm{mm}$ at twenty-four months and $3.67 \pm 1.7 \mathrm{SD} \mathrm{mm}$ at thirty-six months. On the distal side it was $4.01 \pm 0.89 \mathrm{SD} \mathrm{mm}$ at the time of surgery, $3.89 \pm 1.1 \mathrm{SD} \mathrm{mm}$ at twelve months, $3.76 \pm 1.3 \mathrm{SD} \mathrm{mm}$ at twenty-four months and $3.57 \pm 1.8 \mathrm{SD} \mathrm{mm}$ at thirtysix months. This was due to remodeling and maturation of the bone in the new space created around the implant in the maxillary sinus.

The average intra-sinus bone gain was $4.13 \pm 0.97 \mathrm{SD}$ $\mathrm{mm}$ at the time of surgery, $3.90 \pm 1.15 \mathrm{SD} \mathrm{mm}$ at twelve months, $3.74 \pm 1.05 \mathrm{SD}$ mm at twenty-four months and $3.62 \pm 1.75 \mathrm{SD} \mathrm{mm}$ at thirty-six months.

\section{Discussion}

Bone gain results in this study agree with those pub- lished by other authors who have carried out maxillary sinus augmentation using osteotomes of between $4.5 \mathrm{~mm}$ and $6.5 \mathrm{~mm}$ in posterior sectors where bone density is low (13-17).

In studies made with cadavers, Blanco and colleagues obtained an intra-sinus bone increase of 4-8 $\mathrm{mm}$ in height and they evaluated the bone density achieved using osteotomes $(39.38 \pm 9.67 \mathrm{SD} \mathrm{mm})$, comparing this with the density achieved using drills $(31.06 \pm 5.9 \mathrm{SD}$ $\mathrm{mm})$.

In the present study, sinus elevation was carried out via the alveolar ridge, with collagenated porcine bone grafts and immediate implant placement in a single surgical session through the use of angled osteotomes, threaded and with depth markings and restored eighteen weeks later.

This is relatively similar to the 3.1 months described by Nedir et al. using BAOSFE (bone-added osteotome sinus floor elevation) technique (although he did not state what biomaterial is adequate for this technique), who obtained increases to intra-sinus bone of $4.6 \mathrm{~mm}$ on the mesial side and 5.2 on the distal (19). A further factor which reduces healing time is the use of implants with rough surfaces which accelerate implant osseointegration to regenerated bone.

With respect to implant length, our results are similar to those obtained by Ferrigno and colleagues, who state that short implants of $8 \mathrm{~mm}$ have similar success rates to implants of 10 and $12 \mathrm{~mm}$ placed using osteotomes. Lastly, it is important to bear in mind the complications that may arise from maxillary sinus floor elevation when using osteotomes for implant placement, such as chronic sinusitis and benign paroxysmal positional vertigo (as described by Peñarrocha et al.), which is due to trauma induced by the percussion forces generated when the osteotome is hammered (20).

\section{Conclusions}

The use of angled osteotomes, threaded and with depth markings allowed the creation of intra-sinus space filled with biomaterial of $4.13 \pm 0.97 \mathrm{SD} \mathrm{mm}$ at the time of surgery, $3.90 \pm 1.15 \mathrm{SD} \mathrm{mm}$ at twelve months, $3.74 \pm$ $1.05 \mathrm{SD}$ mm at twenty-four months and $3.62 \pm 1.75 \mathrm{SD}$ $\mathrm{mm}$ at thirty-six months. Bone remodeling decreased by $0.51 \pm 0.08 \mathrm{SD} \mathrm{mm}$ over thirty-six months due to resorption of fibrin in the implant's apical portion and increased bone density at the new sinus floor. The alveolar maxillary sinus floor elevation technique with osteotomes and collagenated porcine MP3 bone achieved a success rate of $96.6 \%$ after a follow-up period of thirtysix months monitoring both implants and prosthesis. The advantage of the osteotome technique is that it is a less invasive technique with a lower risk of complications both during and following surgery. 


\section{References}

1. Rambla-Ferrer J, Peñarrocha-Diago M, Guarinos-Carbó J. Analysis of the use of expansion osteotomes for the creation of implant beds. Technical contributions and review of the literature. Med Oral Patol Oral Cir Bucal. 2006;11:E267-71.

2. Sorní M, Guarinós J, García O, Peñarrocha M. Implant rehabilitation of the atrophic upper jaw: a review of the literature since 1999. Med Oral Patol Oral Cir Bucal. 2005;10 Suppl 1:E45-56.

3. Aguirre Zorzano LA, Rodríguez Tojo MJ, Aguirre Urizar JM. Maxillary sinus lift with intraoral autologous bone and B--tricalcium phosphate: histological and histomorphometric clinical study. Med Oral Patol Oral Cir Bucal. 2007;12:E532-6.

4. Jensen SS, Broggini N, Hjørting-Hansen E, Schenk R, Buser D. Bone healing and graft resorption of autograft, anorganic bovine bone and beta-tricalcium phosphate. A histologic and histomorphometric study in the mandibles of minipigs. Clin Oral Implants Res. 2006;17:237-43.

5. Kirmeier R, Payer M, Wehrschuetz M, Jakse N, Platzer S, Lorenzoni M. Evaluation of three-dimensional changes after sinus floor augmentation with different grafting materials. Clin Oral Implants Res. 2008;19:366-72.

6. Hernández-Alfaro F, Torradeflot MM, Marti C. Prevalence and management of Schneiderian membrane perforations during sinuslift procedures. Clin Oral Implants Res. 2008;19:91-8.

7. Boyne PJ, James RA. Grafting of the maxillary sinus floor with autogenous marrow and bone. J Oral Surg. 1980;38:613-6.

8. Siddiqui AA, Sosovicka M. Lateral bone condensing and expansion for placement of endosseous dental implants: a new technique. J Oral Implantol. 2006;32:87-94.

9. Aghaloo TL, Moy PK. Which hard tissue augmentation techniques are the most successful in furnishing bony support for implant placement?. Int J Oral Maxillofac Implants. 2007;22 Suppl:49-70.

10. Summers RB. A new concept in maxillary implant surgery: the osteotome technique. Compendium. 1994;15:152, 154-6, 158.
11. Summers RB. The osteotome technique: Part 3--Less invasive methods of elevating the sinus floor. Compendium. 1994;15:698, 700, 702-4.

12. Albrektsson T, Zarb G, Worthington P, Eriksson AR. The longterm efficacy of currently used dental implants: a review and proposed criteria of success. Int J Oral Maxillofac Implants. 1986;1:1125.

13. Schmidlin PR, Müller J, Bindl A, Imfeld H. Sinus floor elevation using an osteotome technique without grafting materials or membranes. Int J Periodontics Restorative Dent. 2008;28:401-9.

14. Fermergård R, Astrand P. Osteotome sinus floor elevation and simultaneous placement of implants--a 1-year retrospective study with Astra Tech implants. Clin Implant Dent Relat Res. 2008;10:62-9.

15. Toffler M. Osteotome-mediated sinus floor elevation: a clinical report. Int J Oral Maxillofac Implants. 2004;19:266-73.

16. Ferrigno N, Laureti M, Fanali S. Dental implants placement in conjunction with osteotome sinus floor elevation: a 12-year life-table analysis from a prospective study on 588 ITI implants. Clin Oral Implants Res. 2006;17:194-205.

17. Calvo-Guirado JL, Saez-Yuguero R, Pardo-Zamora G. Compressive osteotomes for expansion and maxilla sinus floor lifting. Med Oral Patol Oral Cir Bucal. 2006;11:E52-5.

18. Blanco J, Suárez J, Novio S, Villaverde G, Ramos I, Segade LA. Histomorphometric assessment in human cadavers of the peri-implant bone density in maxillary tuberosity following implant placement using osteotome and conventional techniques. Clin Oral Implants Res. 2008;19:505-10.

19. Nedir R, Bischof M, Vazquez L, Nurdin N, Szmukler-Moncler S, Bernard JP. Osteotome sinus floor elevation technique without grafting material: 3 -year results of a prospective pilot study. Clin Oral Implants Res. 2009;20:701-7.

20. Peñarrocha-Diago M, Rambla-Ferrer J, Perez V, Pérez-Garrigues $\mathrm{H}$. Benign paroxysmal vertigo secondary to placement of maxillary implants using the alveolar expansion technique with osteotomes: a study of 4 cases. Int J Oral Maxillofac Implants. 2008;23:129-32. 